\title{
Exploring Teacher Assessment Literacy in EFL Classroom
}

\author{
Wa Ode Sitti Wardani ${ }^{1}$, Didi Sukyadi ${ }^{2}$, Pupung Purnawarman ${ }^{3}$ \\ \{waodesittiwardani19@upi.edu' ${ }^{1}$,dsukyadi@upi.edu ${ }^{2}$, pupung@upi.edu ${ }^{3}$ \} \\ Department of English Language Education, Indonesia University of Education, Indonesia ${ }^{1,2,3}$
}

\begin{abstract}
In the learning process, teachers are expected to overcome the various challenges and expectations that arise in conducting classroom assessment. Therefore, teachers should have assessment literacy skills in order to be able to carry out assessment practices according to the test standardized used in the education system. However, sometimes pre-service teachers do not have a good preparation in conducting classroom assessment therefore the mistakes often arise. Thus, this study aimed to explored teachers' understanding of assessment literacy and the extent of teachers' understanding of assessment literacy. The sample of the study was 6 pre-service EFL teachers who taught English in public schools and private schools in Raha and Kendari City, Southeast Sulawesi. This study used descriptive analysis to recognize pre-service EFL teachers' understanding of assessment literacy. The findings showed that pre-service teachers had a good understanding of assessment literacy but it was still in the medium level category. Thus, pre-service teachers should carry out self-development in classroom assessment practices in order to conduct the appropriate assessment instruction in the teachinglearning process.
\end{abstract}

Keywords: Assessment literacy, Teacher assessment literacy, Teacher assessment literacy in EFL classroom.

\section{Introduction}

In the learning process, assessing student performance is one of the important teachers' tasks in the classroom. Generally, assessment has used as an important factor in determining student success in the learning process [1]. It is to show the differences of students' abilities in learning process. In addition, it is as guidance in determining the students' rank depend on students' achievement level. It is in line with the statement that assessing student performance in learning is an essential part of teaching. The good students' assessment reflects the successful of teaching practices [2]. However, to carry out a good assessment the teacher should have good knowledge and skills regarding assessment therefore, teachers can accomplish proper assessment instructions. In addition, using appropriate technique and practice in assessment can improve the teachers' ability in designing proper assessment instructions. Then, it can rise students' motivation in learning because the assessment instructions reflect the learning material have learned previously therefore it can increase the students' achievement level in the classroom from time to time [3]. Hence, it is very important for teachers to master assessment literacy skills then teachers can accomplish classroom assessment practices during the learning process or conduct the assessment at the end of the learning process conferring students' level.

Assessment literacy refers to the teachers' ability to plan, manage and implement assessment results accurately and efficiently [4]. It shows that teacher should consider the whole 
aspects in classroom assessment then teachers can be literate in conducting classroom assessment. The assessment literacy skill is very important for teachers to develop in teaching practices. By having assessment literacy skills, teachers can apply appropriate instruction in exploring the level of students' ability during the learning process. In addition, teachers can continue to improve and develop instructions that applied in classroom assessment. It shows that assessment literacy refers to teachers' ability to understand, analyze and apply information about students' performance in order to improve the instructions in classroom assessment [5]. If teachers have good assessment literacy skill, the more comfortable teaching-learning process will be created because the good teaching-learning environment cannot be created without appropriate assessment practices [6]. It based on the positive and negative wash-back effect of National examination at the end of learning process period where the teachers' role is crucial in the student success during the educational process [4]. It is because the students' achievement as the representation of successful teaching and learning process has completed. However, the pre-service teachers in carrying out classroom assessment are still not in accordance with the applicable test standardized in education system. It is because pre-service teachers do not have enough knowledge about classroom assessment therefore it affects the teachers' practices in carrying out classroom assessment. In addition, the teacher lacks expertise in constructing tests to carry out in the classroom because teachers do not use valid evaluation procedures [7]. Therefore, the pre-service teacher should be possessed the assessment literacy skill in order to conduct the appropriate instructions in classroom assessment.

Under these conditions, researcher found out about the teachers' understanding on assessment literacy therefore the researcher can realize the extent of pre-service teachers' understanding on assessment literacy skill and identify the teachers' level in assessment literacy.

\section{Literature Review}

\subsection{Assessment Literacy}

Assessment plays a crucial role in the teaching-learning process because through assessment teachers can realize the extent of the successful in teaching-learning process. It is in line with the statement from Fard and Tabatabaei stated that students' assessment is an important responsibility for teachers because it can help teachers to understand, analyze students and help students to get positive consequences in the teaching field [2]. Therefore, it can help teachers make the right decisions about students' grade, grouping, placement and instruction through various assessment methods. In addition, the assessment is conducted in order the teacher can evaluate the teaching-learning process. Thus, the assessment conducted should meet the assessment standards in education system then it has reliability and validity level in accordance with the conditions of the students in the classroom. To conduct good assessment, teachers should be equipped with competent knowledge in assessment. Consequently, assessment literacy is a complete skill that can support teachers in developing classroom assessment. The assessment literacy is the teachers' ability to apply classroom assessment appropriately and accurately. In addition, assessment literacy define as the acquisition of knowledge, skills and principles of test construction, interpretation and use of the tests, test evaluations, and classbased assessments in addition to developing a critical attitude about the function of valuation in the context of greater education [8]. The assessment literacy consists of three phases, namely: teachers' concept of assessment, teachers' knowledge and skill and teachers' classroom practice of assessment [9]. Teachers are mastering the assessment literacy skill if the teachers have prior 
knowledge on assessment and conducting the assessment practices in appropriate ways. However, Taylor stated that there are eight dimensions included in language assessment literacy, namely: knowledge of theory, technical skills, principles and concepts, language pedagogy, sociocultural values, local practices, personal beliefs, score and decision-making [10]. It shows that teachers in conducting the assessment practices should consider some aspects in assessment. As a result, to master further about assessment literacy skill, teachers should know whole aspects in assessment then teachers could said that teachers have good assessment literacy skill. Generally, the assessment literacy has engaged all stakeholders in education system that more emphasize on knowledge, skills, principles related to assessment of language skill [11]. The term of assessment literacy should be possessed by teachers in this era as the implication of global view of language assessment proposed by Davies [12] which as the development of the trends in language assessment textbook. It shows that there is an innovation in knowledge and skill on knowledge-informed skill and the principles of informed skill. In addition, to conduct the assessment literacy successfully in the classroom teacher should consider the relationship of three dimensions in assessment literacy and the questions that should be answered [9]. Firstly, the practice refers to the teacher should do and the purpose of carrying out the assessment. Secondly, the concepts refer to the theory and standardized tests used by teachers. Thirdly, the context refers to the learners' understanding and orientation in assessment and the context for the practice of assessment in teaching. Therefore, in conducting assessment practices in the classroom, the teacher should consider the three dimensions of assessment literacy then teachers can carry out assessment practices appropriate with the students' needs and test takers' level.

Several studies have conducted in this field. The development approach in classroom assessment literacy should be improved [13]. Therefore, teachers need to develop language assessment literacy teachers can explore and evaluate their own prejudices, to understand the interpretive nature of the phenomenon of assessment and to become increasingly aware of their own dynamic knowledge framework, understanding, values, which form their conceptualizations, interpretations, assessments and decisions in the assessment and learning of their students' second language [14]. It is because some teachers suffer from the poor implementation of classroom assessment literacy even though the role of assessment is very important in the learning process. Then, the classroom assessment should be the main concern of all stakeholders in education to support the implementation of appropriate classroom assessment and in accordance with the students' conditions. It is because the good classroom assessment practices reflected the success of the applicable education system.

\subsection{Teacher Assessment Literacy}

In this era, the education system requires teachers to make various innovations in assessment instruction. Thereupon, the teacher should be able to design valid and reliable assessments that possible to be applied in learning in order to measure the successful of students' learning process and the effectiveness of the teaching [15]. In other words, teachers should have the ability to manage, understand and apply assessment results accurately and efficiently [16][18]. By having adequate knowledge, teachers can take a role in integrating assessment into teaching therefore can produce appropriate assessment techniques in teaching [1]. Then, the teachers who have been literate in assessment will set the classroom activities based on three major concepts, namely setting assessment goals based on students' interests, conducting assessment dynamically through class assignments and providing feedback [3]. Therefore, teachers who have mastered assessment literacy skill properly will consider the three assessment concepts therefore the teachers can carry out classroom assessment successfully. 
Literacy assessment skills are very important to discuss in this era to overcome the practice of assessment conducted by teachers not in accordance with the assessment standards [19],[20]. Thus, it also has an impact on pre-service teachers who tend to use assessments that are not in accordance with the assessment standards because teachers assume that the assessment practices used for generations [21],[22]. Then, pre-service teachers should be equipped with sufficient ability regarding the implementation of the assessment in order to avoid assessment practices that are not in accordance with the assessment standards. In addition, a variety of current knowledge about assessment should continue to develop through self-development activities in order to fulfill students' critical thinking skills [23]. In mastering the assessment literacy skill, teacher should consider two important components in teaching practices, namely: the knowledge base refers to what teachers need to know) and the complex process of language teacher education refers to how they learn and develop it then teachers can know how to develop teachers' assessment literacy skill. It deals with two goals, namely: transforming teachers' assessment practices and understanding the phenomenon of assessment itself and the teachers as assessor for themselves [24]. The knowledge, skills, and abilities are the guidance for teachers in conducting the assessment. Therefore, the whole aspects in assessment are very important to know by teachers in education system [9].

A series of previous studies found that many teachers were not train in the implementation of classroom assessment so teachers lacked knowledge of assessment. In other hand, teachers who have assessment literacy skills will affect the teacher's reflective teaching practice where the higher the assessment literacy held by the teacher, the higher the reflective teaching [1]. In addition, there are many recommendations from previous research to improve assessment literacy skills that integrate knowledge, skills, and principles in procedural texts that seek to balance the need for class and normative assessment [9]. It shows that the assessment literacy develop every time in accordance with the current trends in education field therefore it could meet the students' needs in the learning process.

\subsection{Teacher Assessment Literacy in EFL Classroom}

In teaching-learning process, if the teachers want to take over all activities in the classroom as well as the assessment then the teachers should have assessment literacy skill [15]. In accordance with curriculum 2013, the practice of classroom assessment has undergone a change where the teachers observe student successful not only from the students' knowledge. However, the teacher should evaluate students' attitude, knowledge and skills. Therefore, teachers should conduct a comprehensive assessment in accordance with established national education standards. In addition, the number of English learning models and assessments where each skill in language learning has the different treatment then assessment methods used are also different. It requires teachers to continue develop their skills in designing and evaluating assessments that are appropriate to used [12]. However, the role of classroom assessment in EFL is very challenging for teachers [25],[26]. In addition, the classroom assessment can provide the controlling effect on teaching-learning process [27]. In the classroom, teachers can spend as much as $20 \%$ or $30 \%$ in assessment related activities [28]. It shows that teachers spend a lot of time to design and conduct the assessment activity in the classroom. It is because the successful of assessment in the classroom supported by good enough teachers' capability in conducting assessment. However, some aspects influence the quality classroom assessment. Firstly, the external test. Then, teachers' assessment literacy skill. Thirdly, the classroom realities [29],[30]. The external tests greatly affect the lesson plan, learning goals and performance assessment [29],[31]. The other challenges can influence the misconception of teachers, students, and education units about assessment are the inaccuracies of assessment given therefore it does not 
match the learning process in certain level. Thus, it does not support students' motivation and learning enthusiasm [32]. Then, the lack of teachers' knowledge in quality assessment practices because teacher preparation courses and professional training do not prepare teachers well for classroom assessment [29],[33],[32],[30]. In addition, inappropriate behavior of students and heterogeneity of students' abilities also influence the implementation of assessment in the classroom [29]. In addition, crowded classroom and limited learning time in the classroom are mainly in public schools also influence the classroom assessment practices [34]. Moreover, to achieve an increase in student achievement, several programs that should take in order to promote the improvement of classroom assessment quality. Firstly, training programs for teachers should have more courses that are intensive on assessment literacy in order to prepare teachers well to face the challenges of classroom assessment. Secondly, the practice of classroom assessment should transform into an assessment for learning [29],[35]-[37]. In each level, the quality of learning assessment leads to greater student achievement [27]. Hence, to improve the quality of assessment, educational institutions should support teachers in developing their assessment skills by providing various training programs regarding assessment. It is because the previous research shows that the training in assessment literacy still include few program. The training held should prioritize pre-service teachers and in-service teachers in improving the development of assessment quality. Besides, an evaluation of the implications from training activities should be carry out therefore teachers could know the extent of their progress in classroom assessment. Consequently, the quality of classroom assessment always increases in every time.

Several previous studies have suggested that the understanding of pre-service teachers who have taken the assessment course is superior to in-service teachers in the assessment of attitudes, knowledge, and skills [38]. It shows that teachers who have participated in various teaching skills development will be superior in understanding classroom assessment. In other hand, even though the teachers have a positive attitude towards the implementation of assessment but the teachers still have low literacy assessment skill [39]. In addition, in increasing teacher assessment literacy, cooperative learning approaches and teamwork can carry out in which people who have sufficient knowledge in assessment act as mentors. It shows that cooperative learning and teamwork can be an alternative to increase teachers' assessment literacy skills in order to conduct the appropriate assessment practices in the classroom [13]. It is supported by Scarino [14] emphasized that it is important to increase assessment literacy in a way that can help teachers explore more about the phenomena in assessment therefore teachers can form values that can be used as a guidance for teachers in carrying out classroom assessments during undergoing their teaching careers. Therefore, assessment literacy skill is very important for preservice teachers and inservice teachers in order to conduct the appropriate assessment instruction in the classroom.

\section{Methodology}

\subsection{Research Design}

The research design of the study was using descriptive analysis. This study were designed to identify teachers' understanding on assessment literacy and the extent of teachers' understanding on assessment literacy in EFL classroom by using Classroom Assessment Literacy Inventory Questionnaire adapted from Mertler [40]. By answering the question items from the questionnaire, researcher could know the teacher assessment literacy in EFL 
classroom. Thus, researcher could draw conclusions to what extent the teachers' understanding on assessment literacy and the teachers' level in knowing assessment literacy.

\subsection{Participants}

The participants of the study were 6 pre-service teachers whose ages range 23-25 years old and who have taught English for approximately 4 months- 2 years in various levels of education. Participants in this study focus on pre-service teachers who undertake teaching activities in public schools or private schools in two different cities, namely Raha and Kendari. These two cities were located in Southeast Sulawesi that was one of the provinces in Indonesia in the Southeast part of Sulawesi Island with the capital city Kendari. Teachers who participated in this study were fresh graduated about one or two years ago completing their bachelor degree in English education major. In addition, one of the teachers started teaching activities in one of private school located in Kendari, Southeast Sulawesi while studying. Meanwhile, some teachers started teaching activities in public schools or private schools when the teachers have completed their bachelor degree in English education major. As a result, teachers' experience in starting teaching career was still very beginning and fresh then it was necessary to explore further the teachers' knowledge and skills about classroom assessment. Then, the pre-service teachers have mature readiness in starting teaching activities even though the teachers had occupied language-testing course during their studies. However, it did not yet reflect that the teachers had a well-prepared readiness in terms of both knowledge and skills in conducting classroom assessment. As a result, it is important to identify the teachers' background knowledge and skills in classroom assessment in order to prepare the pre-service teachers to be professional in conducting classroom assessment practices.

\subsection{Instrument}

The instrument of the study was using Classroom Assessment Literacy Inventory questionnaire proposed by Mertler [40]. The questionnaire were divided into two parts which part I consisted of items related to teachers' background and part II consisted of 14 multiple choice items with four options related to knowledge of standardized testing and the remaining items were related to classroom assessment. One option can be the correct answer and it was alligned with "Standards for Teacher Competence in Educational Assessment of Students", namely choosing assessment methods, administering assigning and interpreting learning outcomes, using assessment outcomes in decision making, using assessment to determine levels of learning outcomes, communicating assessment outcomes, and knowing unethical practices.

The questionnaire used to recognize teacher knowledge, basic elements and principles in educational assessment. Accordingly, researcher could identify the teachers' knowledge and skills in classroom assessment practices related with the test standardized in education system.

\subsection{Procedure}

In collecting data, researcher distributed the questionnaire to 10 pre-service teachers who completed their studies about one or two years ago and the teachers are currently undergoing teaching activities in formal and semi-formal school institutions at this time. However, only six teachers respond the questionnaire. In addition, the questionnaire designed in a Google form then shared via WhatsApp account of pre-service teachers. The teachers accessed the link and filled in the personal information related to the teachers' personal background. Then, the teachers answered the questions related to the teachers' knowledge in conducting an appropriate 
assessment with the standardized test in education system directly by selecting one of the correct answers to the questions asked. In this case, the teachers answer the questions according to their experiences in conducting classroom assessment. For that reason, every teacher has different answer in responding each question.

\subsection{Data Analysis}

In this study, the data analysis was used the percentage of each questionnaire to know the teachers' understanding of assessment literacy. Through percentage of the questionnaire researcher could analyze the extent of knowledge and skills possessed by the teachers in carrying out classroom assessment. Then, the researcher calculated the mean score of each item based on the standard used in assessment literacy therefore the researcher could know the level of teachers' assessment literacy. Hence, the researcher could know the assessment literacy skill possessed by pre-service teachers who have teaching experience around 4 months 2 years which category belongs.

\section{Findings and Discussions}

\subsection{Findings}

Teachers' Understanding on Assessment Literacy in EFL Classroom. In accordance with the questionnaire used by researcher in collecting data divided into two parts, namely: preservice teachers' personal background and teacher knowledge about aspects of classroom assessment in line with the assessment standards used. The researcher finds out several things as follows:

Table 1. Pre-service Teachers' Background

\begin{tabular}{lllll}
\hline Respondent & Gender & Age & Teaching Experience & Level of Teaching \\
\hline Respondent 1 & Female & 24 & 2 years & Private School \\
Respondent 2 & Female & 23 & 2 years & Private School \\
Respondent 3 & Male & 23 & More than 1 year & Junior High School \\
Respondent 4 & Female & 24 & 1 year & Elementary School \\
Respondent 5 & Female & 24 & 4 months & Junior High School \\
Respondent 6 & Female & 23 & 1 year & Junior High School \\
\hline
\end{tabular}

Based on the table, it shows that the respondents in this study consist of 5 female teachers and one male teacher. The age range of the teachers is around 23-24 years old and they have teaching experience around 4 months to 2 years. As pre-service teachers, of course the teaching experience in this period has carved a lot of stories and experiences in teaching. From this table, it shows that four teachers teach in public schools (elementary schools and junior high schools) and two others teach in private schools. In addition, English teachers in private schools teach in various students' level, namely: elementary school, junior high school, senior high school and university. Therefore, it shows that at least teachers have a long enough experience that can support the development of teaching skills in various aspects of teaching. However, sometimes the span of teaching experience does not always support the teacher in mastering effective teaching skills. 
Table 2. Teachers' Score of Classroom Assessment Literacy

\begin{tabular}{lccccc}
\hline \multirow{2}{*}{ Standard } & \multirow{2}{*}{ Items } & \multicolumn{5}{c}{ Score } \\
\cline { 3 - 6 } & & $\mathbf{1}$ & $\mathbf{2}$ & $\mathbf{3}$ & $\mathbf{4}$ \\
\hline \multirow{2}{*}{ Choosing assessment methods } & Q1 & $33.3 \%$ & - & $66.3 \%$ & - \\
Developing assessment & Q2 & $16.7 \%$ & $16.7 \%$ & - & $66.7 \%$ \\
methods & Q3 & $66.7 \%$ & $33.3 \%$ & - & - \\
Administering assigning and & Q4 & $16.7 \%$ & $16.7 \%$ & $16.7 \%$ & $50 \%$ \\
interpreting learning & Q5 & $50 \%$ & $16.7 \%$ & $16.7 \%$ & $16.7 \%$ \\
outcomes & Q6 & $33.3 \%$ & $33.3 \%$ & - & $33.3 \%$ \\
Using assessment outcomes & Q7 & $16.7 \%$ & - & $50 \%$ & $33.3 \%$ \\
in decision making & Q8 & $33.3 \%$ & $16.7 \%$ & - & $50 \%$ \\
Using assessment to & Q9 & $16.7 \%$ & $16.7 \%$ & $33.3 \%$ & $33.3 \%$ \\
determine levels of learning & Q10 & $16.7 \%$ & $66.7 \%$ & - & $16.7 \%$ \\
outcomes & & & & & \\
Communicating assessment & Q11 & $33.3 \%$ & $16.7 \%$ & $50 \%$ & - \\
outcomes & Q12 & - & $33.3 \%$ & $16.7 \%$ & $50 \%$ \\
Knowing unethical practices & Q13 & $50 \%$ & - & $33.3 \%$ & $16.7 \%$ \\
& Q14 & - & $33.3 \%$ & $50 \%$ & $16.7 \%$ \\
\hline
\end{tabular}

Based on the table shows that the ability of teachers in choosing assessment methods is very good where the teacher can choose the method in accordance with the objectives from the implementation of assessment in order to achieve the learning objectives. In choosing this assessment method, the teacher should really consider that the instruments used are in accordance with the purpose of the assessment. In other side, teachers still have not shown a good response in developing assessment methods that suitable with the appropriate instruments. It is because teachers do not have sufficient experience regarding the development of assessment methods.

Furthermore, in administering assigning and interpreting learning outcomes, some teachers still do not have sufficient abilities because teachers still seem confused in interpreting learning outcomes based on the tests given. In other hands, in determining decisions based on the results of classroom assessments already have adequate abilities where the teacher can determine the best decision based on the problems given related to assessment in the classroom. In determining the level of student learning outcomes based on assessments given, the teacher can interpret well according to student scores. In this case, the teacher should really interpret student-learning outcomes based on the results of the assessment in order to be able to evaluate the learning process that has done. Therefore, teachers can find out whether the learning process has been successful or not.

To find out whether the assessment has met the assessment objectives that have designed, the teacher expected to be able to communicate the results of the assessment by interpreting student scores in accordance with the assessment standards used. Of course, in conducting the assessment should meet the code of ethics in carrying out assessments in the classroom, the teacher should have knowledge of ethical and unethical practices carried out in classroom assessment. Based on the result, researcher find that the teachers have not been able to determine the actions that should be done and do not in carrying out the assessment in the classroom. It is because the teacher still does not have background knowledge regarding appropriate actions in carrying out classroom assessments. 
In brief, the classroom assessment literacy of pre-service teacher in the classroom shows the good responses. However, it is important to develop the knowledge about carrying out the classroom assessment in order to conduct the appropriate assessment based on the standard from educational system. It is because there are some parts of the standard assessment that have not achieved by teachers and show that they already have good assessment literacy.

\section{The Extent of Teachers' Understanding on Assessment Literacy in EFL Classroom.}

Table 3. Levels of Classroom Assessment Literacy

\begin{tabular}{lccc}
\hline \multicolumn{1}{c}{ Standard } & \multicolumn{2}{c}{ Classroom Assessment Literacy } \\
\cline { 2 - 4 } & Low & Medium & High \\
\hline $\begin{array}{l}\text { Choosing assessment methods } \\
\text { Developing assessment } \\
\text { methods }\end{array}$ & - & $66.7 \%$ & - \\
$\begin{array}{l}\text { Administering assigning and } \\
\text { interpreting learning outcomes }\end{array}$ & - & $58.5 \%$ & - \\
$\begin{array}{l}\text { Using assessment outcomes in } \\
\text { decision making }\end{array}$ & - & $41.65 \%$ & - \\
$\begin{array}{l}\text { Using assessment to determine } \\
\text { levels of learning outcomes }\end{array}$ & - & $50 \%$ & - \\
$\begin{array}{l}\text { Communicating assessment } \\
\text { outcomes }\end{array}$ & - & $41.7 \%$ & - \\
Knowing unethical practices & $33.35 \%$ & $50 \%$ & - \\
\hline
\end{tabular}

The table shows that the assessment literacy skills possessed by pre-service teachers in EFL classroom are still in medium level. It means that teachers should continue to develop their assessment literacy skills by attending various training programs that can support selfdevelopment. In addition, there are still low levels of assessment practices conducted by teachers in the classroom. It caused by various factors, namely: teaching experience, teacher preparation in teaching, and lack of self-evaluation at the end of the learning process therefore inaccuracies in carrying out assessments still occur in teaching practices.

Overall, pre-service teachers with teaching experience within 4 months- 2 years have shown a good response. However, the attitude in improving assessment literacy skills should continue especially for pre-service teachers who have just entered the world of teaching in the classroom.

\subsection{Discussion}

Based on the results of the study, teacher assessment literacy should possessed by both preservice teachers and in-service teachers. In 21st century, assessment literacy skills should increase to encounter the students' needs in the classroom. In this case, the teacher should carry out various innovations in classroom assessment in order to achieve the desired learning goals. It is in line with what Fard and Tabatabaei found in their study which teachers do not yet have adequate assessment literacy skills due to lack of teacher preparation when teaching in the classroom [2]. It is in line what Muhammad et al. said that teachers are not prepared well to assess students' performance appropriately and determine the right level of assessment [34]. In addition, various conspiracies that have carried out in the previous learning process are still a habit that is used by pre-service teachers and in-service teachers. In fact, pre-service teachers as new graduates of education should bring new changes in the classroom in accordance with the current education system. In other hand, Mellati and Khademi found that teacher assessment 
literacy affects student-learning achievement in writing skill [3]. In addition, it can influence teachers' awareness in preparing the teaching environment into an effective and efficient assessment in accordance with the language skills have taught. Therefore, it is very important for teachers to raise their readiness in carrying out effective assessment in accordance with the language skills have taught.

Then, teachers should possess the assessment literacy skill because it is a way to promote the effective teaching-learning process in accordance with the education standards. Most of teachers conduct the appropriate instruction in assessment automatically will increase the teaching practices in the classroom. The appropriate assessments' instruction will lead students to know their progress in learning how extent they have engaged in learning process. Therefore, mastering assessment literacy skill will help students in acquiring the learning objectives.

\section{Conclusion}

The conclusion of the study shows that teachers have good responses on assessment literacy. However, the assessment literacy skills still categorized in medium level. It shows that pre-service teachers do not have well enough yet classroom assessment practices even the teachers are new graduate. It is because the teachers do not have good preparation in teaching especially in organizing the assessment. In addition, the teaching experience also influenced the teachers' skill in conducting the appropriate assessment. Therefore, pre-service teachers should have a high desire to improve assessment literacy skills by participating in several activities that can support the development of their knowledge and skills in assessment.

In this study, researcher strongly recommends pre-service teachers in 21 st century to develop themselves in teaching practices, especially assessment literacy skills by joining some training in language assessment. It is because language assessment training is not only to foster assessment literacy skills but also to equip pre-service teachers with the ability of basic knowledge, skills, and principles in handling large-scale assessments and efficient classroombased assessment. In addition, mastering assessment literacy can help teachers to utilize assessment results in order to promote student successful in learning process (Lam, 2015).

Acknowledgments. The authors would like to express their thanks to the EFL teachers in public school and private school of Raha and Kendari, Southeast Sulawesi who contributed to the work as the participants of the study.

\section{References}

[1] Ashraf, H., \& Zolfaghari, S. EFL Teachers' Assessment Literacy and Their Reflective Teaching. International Journal of Instruction. 2018. 11 (1), 425-436.

[2] Fard, Z. R., \& Tabatabaei, O. Investigating Assessment Literacy of EFL Teachers in Iran. Journal of Applied Linguistics and Language Research. 2018. 5(3), 91-100.

[3] Mellati, M., \& Khademi, M. Exploring teachers' assessment literacy: Impact on learners' writing achievements and implications for teacher development. Australian Journal of Teacher Education. 2018. 43(6), 1.

[4] Kiomrs, R., Abdolmehdi, R., \& Rashidi, N. On the Interaction of Test Washback and Teacher Assessment Literacy: The Case of Iranian EFL Secondary School Teachers. English Language Teaching. 2011. 4(1), 156-161. 
[5] Falsgraf, C. Why a national assessment summit? New visions in action. National Assessment Summit. Meeting conducted in Alexanderia, Va. 2005.

[6] Eckhout, T., Davis, S., Mickelson, K., \& Goodburn, A. A method for providing assessment training to in-service and pre-service teachers. Annual Meeting of the Southwestern Educational Research Association in New Orleans. LA. 2005.

[7] Yan, Z., \& Cheng, E. C. K. Primary teachers' attitudes, intentions and practices regarding formative assessment. Teaching and Teacher Education. 2015. 45, 128-136.

[8] O'Loughlin, K. Developing the assessment literacy of university proficiency test users. Language Testing. 2013. 30(3), 363-380.

[9] Fulcher, G. Assessment literacy for the language classroom. Language Assessment Quarterly. 2012. 9(2), 113-132.

[10] Taylor, L. Communicating the theory, practice and principles of language testing to test stakeholders: Some reflections. Language testing. 2013. 30(3), 403-412.

[11] Giraldo, F. Language assessment literacy: Implications for language teachers. Teachers Professional Development. 2018. 20(1), 179-195.

[12] Davies, A. Textbook trends in teaching language testing. Language testing. 2008. 25(3), 327-347.

[13] Yamtim, V., \& Wongwanich, S. A study of classroom assessment literacy of primary school teachers. Procedia-Social and Behavioral Sciences. 2014. 116, 2998-3004.

[14] Scarino, A. Developing assessment literacy of teachers of languages: A conceptual and interpretive challenge. Papers in Language Testing and Assessment. 2017. 6(1), 18-40.

[15] Beziat, T.L., \& Coleman, B.K. Classroom assessment literacy: Evaluating pre-service teachers. The Researchers. 2015. 27 (1), 25-30.

[16] Boyle-baise, M. Preparing community-oriented teachers: Reflections from a multicultural servicelearning project. Journal of Teacher Education. 2005. 56 (5), 446-458.

[17] Stiggins, R. J. Assessment, student confidence, and school success. The Phi Delta Kappan. 1999. 81(3), 191-198.

[18] Stoynoff, S., Chapelle, C. A., \& Viii, P. ESOL tests and testing. TESL-EJ. 2005.9 (3).

[19] Galluzzo, G. R. Performance assessment and renewing teacher education the possibilities of the NBPTS standards. The Clearing House: A Journal of Educational Strategies. 2005.78 (4), 142-145.

[20] Mertler, C. A. Secondary teachers' assessment literacy: Does classroom experience make a difference? American secondary education. 2004. 49-64.

[21] Bachor, D. G., \& Baer, M.R. An examination of preservice teachers' simulated classroom assessment practices. Alberta journal of educational research. 2001.47 (3).

[22] Campbell, C., \& Evans, J. A. Investigation of preservice teachers' classroom assessment practices during student teaching. The Journal of Educational Research. 2000.93 (6), 350-355.

[23] Cizek, G. J. Pockets of Resistance in the Assessment Revolution. Educational Measurement: Issues and Practice. 2000. 19 (2), 16.

[24] Scarino, A. Language assessment literacy as self-awareness: Understanding the role of interpretation in assessment and in teacher learning. Language Testing. 2013. 30(3), 309-327.

[25] Mertler, C. A. Teachers' assessment knowledge and their perceptions of the impact of classroom assessment professional development. Improving schools. 2009. 12(2), 101-113.

[26] Mertler, C. A. Classroom assessment: A practical guide for educators. Routledge. 2016.

[27] Stiggins, R. Classroom Assessment Competence: The Foundation of Good Teaching. 2016.

[28] Stiggins, R. J. Revitalizing classroom assessment: The highest instructional priority. The Phi Delta Kappan. 1988. 69(5), 363-368.

[29] McMillan, J. H. Understanding and improving teachers' classroom assessment decision making: Implications for theory and practice. Educational measurement: Issues and practice. 2003. 22(4), 34-43.

[30] Zhang, Z., \& Burry-Stock, J. A. Classroom assessment practices and teachers' self-perceived assessment skills. Applied Measurement in Education. 2003. 16(4), 323-342.

[31] Stiggins, R. Five assessment myths and their consequences. Education Week. 2007. 27(8), 28-29.

[32] Shepard, L. A. The role of assessment in a learning culture. Educational researcher. 2000. 29(7), 414. 
[33] Rogler, D. Assessment Literacy: Building a Base for Better Teaching and Learning. English Teaching Forum. 2014. Vol. 52, No. 3, pp. 2-13.

[34] Muhammad, N., Hama, F., \& Bardakçı, M. Iraqi EFL Teachers' Assessment Literacy: Perceptions and Practices. Arab World English Journal (AWEJ). 2019. Volume, 10.

[35] Stiggins, R. J. Assessment crisis: The absence of assessment for learning. Phi Delta Kappan. 2002. 83(10), 758-765.

[36] Stiggins, R. Assessment manifesto: A call for the development of balanced assessment systems. 2008.

[37] Valencia, S. W. Understanding assessment: Putting together the puzzle. Current Research in Reading/Language Arts. 2002. 30, 2014.

[38] Alkharusi, H., Kazem, A.M., \& Al-Musawai, A. Knowledge, skills, and attitudes of preservice and inservice teachers in educational measurement. Asia-Pacific Journal of Teacher Education. 2011. 39 (2), 113-123.

[39] Alkharusi, H., Aldhafri, S., Alnabhani, H., \& Alkalbani, M. Educational Assessment Attitudes, Competence, Knowledge, and Practices: An Exploratory Study of Muscat Teachers in the Sultanate of Oman. Journal of Education and Learning. 2012. I (2), 217-232.

[40] Mertler, C. A. Preservice Versus Inservice Teachers' Assessment Literacy: Does Classroom Experience Make a Difference? American secondary education. 2003.

[41] Lam, R. Language assessment training in Hong Kong: Implications for language assessment literacy. Language Testing. 2015. 32(2), 169-197. 